\title{
Pengaruh Model Pembelajaran Assurance Relevance Interest Assessment Satisfaction (ARIAS) Berbantuan E-Learning Schoology Terhadap Hasil Belajar TIK
}

\author{
Kadek Fuji Widhi Astrini ${ }^{*}$, Ketut Agustini2 ${ }^{2}$, Made Putrama ${ }^{3}$
}

1,2,3 Pendidikan Teknik Informatika, Universitas Pendidikan Ganesha Singaraja-Bali, Indonesia

\section{A R T I C L E I N F O}

Article history:

Received 19 April 2019

Received in revised form 10 May 2019

Accepted 12 June 2019

Available online 25 July 2019

Kata Kunci:

Assurance Relevance

Interest Assessment

Satisfaction (ARIAS), E-

learning Schoology, Hasil

Belajar, Teknologi Informasi

dan Komunikasi

Keywords:

Assurance Relevance

Interest Assessment

Satisfaction (ARIAS), E-

learning Schoology,

Learning Outcomes,

Information and

Communication Technology

\begin{abstract}
A B S T R A K
Penelitian ini bertujuan untuk mengetahui (1) pengaruh model pembelajaran ARIAS berbantuan e-learning schoology terhadap hasil belajar TIK siswa kelas VIII SMP Saraswati Seririt, (2) respon siswa terhadap model pembelajaran ARIAS berbantuan e-learning schoology terhadap hasil belajar TIK siswa kelas VIII SMP Saraswati Seririt. Jenis penelitian ini adalah eksperimen semu (quasi eksperimen) dengan desain Post Test Only Control Group Design. Metode pengumpulan data yang digunakan yaitu metode tes objektif pilihan ganda dan metode angket atau kuisioner. Data hasil belajar dianalisis melalui uji prasyarat yaitu uji normalitas dan uji homogenitas dengan hasil kedua kelompok berdistribusi normal dan homogen, dilanjutkan dengan uji hipotesis yang menggunakan uji t. Hasil penelitian menunjukkan bahwa (1) terdapat hasil belajar yang lebih tinggi antara siswa yang belajar menggunakan model pembelajaran ARIAS berbantuan e-learning schoology dengan siswa yang belajar tanpa menggunakan model pembelajaran ARIAS berbantuan e-learning schoology pada mata pelajaran TIK kelas VIII SMP Saraswati Seririt. Hasil analisis uji-t memperolej $t_{\text {hitung }} 4,7686$ yang lebih besar dari $t_{\text {tabel }} 1,9977$. Berdasarkan kriteria pengujian ini berarti $\mathrm{H}_{0}$ ditolak, (2) respon siswa dari penggunaan model pembelajaran ARIAS berbantuan e-learning schoology pada mata pelajaran TIK adalah sangat positif dilihat dari rata-rata skor hasil angket respon siswa yaitu 83,89.
\end{abstract}

\section{A B S T R A C T}

This study aims to determine (1) the effect of the ARIAS learning model assisted by e-learning schoology on ICT learning outcomes of eighth grade students of Saraswati Seririt Middle School, (2) students' responses to the ARIAS learning model assisted by e-learning schoology on the learning outcomes of ICT students of VIII SMP Saraswati Seririt. This type of research is quasi-experimental (quasi-experimental) with Post Test Only Control Group Design. Data collection methods used are multiple choice objective test methods and questionnaires or questionnaires. Learning outcomes data were analyzed through prerequisite tests namely normality and homogeneity tests with the results of both normal and homogeneous distribution groups, followed by hypothesis testing using the t test. The results showed that (1) there was a higher learning outcome between students learning to use the ARIAS learning model assisted by e-learning schoology and students learning without using the ARIAS learning model assisted by e-learning schoology in ICT subjects in VIII SMP Saraswati Seririt. The results of the t-test analysis obtained 4.7686 which was greater than 1.9977 table. Based on these testing criteria, it means that $\mathrm{HO}$ is rejected, (2) students' responses from the use of the ARIAS learning model assisted by e-learning schoology in ICT subjects are very positive in terms of the average score of the results of the student response questionnaire that is 83.89 .

\footnotetext{
* Corresponding author.

E-mail addresses: fujiwidhi18@gmail.com (Kadek Fuji Widhi Astrini)
} 


\section{Pendahuluan}

Sumber Daya Manusia (SDM) yang berkualitas merupakan faktor yang penting dalam membangun sebuah negara. Upaya untuk menyiapkan SDM yang berkualitas dan menjadi wadah yang dapat dilihat sebagai alat untuk membangun SDM adalah pendidikan.

Belajar merupakan suatu proses yang kompleks yang terjadi pada diri setiap orang sepanjang hidupnya [1]. Upaya yang dilakukan seorang guru agar lebih kompleks untuk membelajarkan siswa dapat menggunakan pola - pola pembelajaran yang bervariasi. Pada garis besarnya ada tiga pola pembelajaran. Pertama, pola pembelajaran guru dengan siswa tanpa menggunakan alat bantu/bahan pembelajaran dalam bentuk alat peraga. Kedua, pola (guru + alat bantu) dengan siswa. Pola pembelajaran ini guru sudah dibantu oleh berbagai bahan pembelajaran yang disebut alat peraga. Ketiga, pola (guru + media) dengan siswa. Pola pembelajaran ini Guru dapat memanfaatkan berbagai media pembelajaran. Jadi pola pembelajaran bergantian antara guru dan media dalam berinteraksi dengan siswa [2]. Media pembelajaran adalah sarana fisik untuk menyampaikan isi atau materi pembelajaran seperti buku, film, video dan sebagainya [3]. Penggunaan media pembelajaran juga dipengaruhi oleh model pembelajaran yang digunakan agar dapat membantu dan memperjelas materi pembelajaran yang dibahas oleh guru.

Berdasarkan hasil wawancara di SMP Saraswati Seririt terhadap guru pengampu mata pelajaran TIK, diperoleh beberapa masalah terkait dengan pembelajaran TIK di kelas VIII yaitu kurangnya jam pelajaran membuat guru menjadi bingung, sedangkan tujuan pembelajaran yang harus dicapai cukup banyak. Menambah jam mata pelajaran TIK setelah pulang sekolah tidak dapat dilakukan karena siswa pulang sekolah pukul 18:00 wita. Pembelajaran yang menekankan siswa untuk dapat menyampaikan ide atau argumentasi secara lisan belum maksimal, kurang aktifnya siswa dikarenakan kurang percaya diri (self efficacy) dari siswa untuk berbicara di hadapan banyak orang dan siswa takut mengutarakan jawaban yang salah. Pemahaman materi melalui pemantapan kuis atau tes yang diberikan oleh guru kurang membuat hasil belajar meningkat karena guru hanya memberikan kuis atau tes dengan jenis essay. Guru hanya menggunakan media pembelajaran konvensional (LKS) yang hanya menjadikan siswa dan proses belajar mengajar menjadi membosankan dan tidak menarik, selain itu jam sekolah pada siang hari juga membuat siswa menjadi kurang semangat dalam mengikuti pembelajaran, sehingga menyebabkan hasil belajar siswa menjadi belum optimal dan nilai ketuntasan tidak terpenuhi.

Berdasarkan hasil observasi yang dilakukan tersebut, hal yang dibutuhkan saat ini yaitu pemilihan model pembelajaran yang tepat sesuai dengan masalah yang telah dipaparkan. Model pembelajaran yang tepat bertujuan, untuk menciptakan kondisi pembelajaran yang membuat siswa dapat belajar secara aktif dan menyenangkan sehingga hasil belajar siswa meningkat.

Salah satu model pembelajaran yang dapat digunakan untuk meningkatkan hasil belajar siswa adalah model pembelajaran Assurance Relevance Interest Assessment Satisfaction (ARIAS) yang berisi lima komponen yang penting dan diperlukan dalam kegiatan pembelajaran yaitu assurance relevance interest assessment satisfaction komponen satu dan lainnya saling keterkaitan. Kelebihan dari model ARIAS adalah dapat diterapkan pada semua kelas atau tingkatan, kecenderungan belajar siswa menjadi lebih bermakna, lebih berorientasi pada keaktifan, dan diharapkan siswa lebih percaya diri (self efficacy) dalam mengikuti pembelajaran.

Selain model pembelajaran, media pembelajaran juga merupakan salah satu faktor yang mendukung dalam kelancaran proses pembelajaran. Media pembelajaran yang saat ini sering digunakan yaitu e-learning. E-learning sebagai aplikasi web di dunia pembelajaran yang memanfaatkan internet (online) [4]. Salah satu e-learning yang berkembang saat ini yaitu schoology. Schoology merupakan Learning Management System (LSM) berbentuk web sosial yang menawarkan pembelajaran seperti di dalam kelas secara gratis dan mudah digunakan.

Penelitian terkait yang sudah ada antara lain penelitian yang dilakukan oleh Betty M.Turnip \& Zulfa Khairani (2016) yang mengkaji tentang model pembelajaran Assurance Relevance Interest Assessment Satisfaction (ARIAS), Akbar Maharani (2016) yang mengkaji tentang perbandingan ARIAS dan VAK. Begitu pula penelitian yang dilakukan oleh (Yuliana \& Fengki,2019; Ningsih,2018; Utami,R.V,2017; Nur Laila,2017) yang sama-sama mengkaji tentang pengaruh e-learning berbasis schooloy.

Berdasarkan permasalahan di atas, maka penulis tertarik untuk mencoba menerapkan model pembelajaran ARIAS berbantuan e-learning schoology pada mata pelajaran TIK dengan melaksanakan penelitian yang berjudul "Pengaruh Model Pembelajaran Assurance Relevance Interest Assessment Satisfaction (ARIAS) Berbantuan E-Learning Schoology Terhadap Hasil Belajar TIK (Studi Kasus Siswa Kelas VIII SMP Saraswati Seririt Tahun Pelajaran 2018/2019)". 


\section{Metode}

Penelitian ini menggunakan desain penelitian eksperimen semu (quasi experimental) dengan pola dasar post test only control group design. Pada penelitian ini diberikan perlakuan yang berbeda kepada kedua kelas yaitu kelas eksperimen dengan jumlah siswa 34 orang dan kelas kontrol dengan jumlah siswa 32. Kelas eksperimen diberikan perlakuan berupa model pembelajaran ARIAS berbantuan e-learning schoology dan kelas kontrol tanpa menggunakan model pembelajaran ARIAS berbantuan e-learning schoology saat proses pembelajaran berlangsung.

Sebelum menentukan kelas yang akan digunakan sebagai sampel, peneliti melakukan uji kesetaraan terlebih dahulu dengan menggunakan uji-t. Metode pengumpulan data yang digunakan dalam penelitian ini adalah metode tes. Metode tes digunakan untuk mengetahui hasil belajar TIK siswa dengan menggunakan tes objektif pilihan ganda dan metode angket digunakan untuk mengetahui respon siswa terkait dengan penggunaan model pembelajaran ARIAS berbantuan e-learning schoology penggunaan metode angket karena angket atau kuesioner merupakan suatu teknik atau cara pengumpulan data secara tidak langsung (peneliti tidak langsung bertanya-jawab dengan responden) [10]. Adapun Metode dan Instrumen Pengumpulan Data yang digunakan dalam penelitian ini dapat disajikan pada Tabel 1 berikut.

Tabel 1. Metode dan Instrumen Pengumpulan Data

\begin{tabular}{llccl}
\hline Jenis Data & \multicolumn{1}{c}{ Sumber Data } & Metode & Instrumen & \multicolumn{1}{c}{ Waktu } \\
\hline $\begin{array}{l}\text { Hasil Belajar } \\
\text { TIK }\end{array}$ & $\begin{array}{l}\text { Siswa kelompok } \\
\text { eksperimen dan } \\
\text { kelompok kontrol }\end{array}$ & Tes & $\begin{array}{l}\text { Tes hasil belajar } \\
\text { berupa pilihan ganda }\end{array}$ & $\begin{array}{l}\text { Setelah proses } \\
\text { pembelajaran }\end{array}$ \\
Respon siswa & $\begin{array}{l}\text { Siswa kelas } \\
\text { eksperimen }\end{array}$ & Angket & Angket respon siswa & $\begin{array}{l}\text { Setelah proses } \\
\text { pembelajaran }\end{array}$ \\
\hline
\end{tabular}

Perangkat pembelajaran dan instrument penelitian dilakukan pengujian terlebih dahulu untuk mendapat gambaran secara empiric apakah perangkat dan instrumen layak digunakan dalam penelitian. Validasi perangkat pembelajaran dilakukan dengan menentukan validitas isi perangkat pembelajaran, sedangkan validiasi instrument penelitian dilakukan dengan menentukan validitas isi tes, reliabilitas tes, indeks kesukaran butir, indeks daya beda, dan keefektifan pengecoh. Validitas tes ini ditinjau dari validitas isi dan validitas konstruk. Untuk memperoleh tujuan dari proses analisis, data terlebih dahulu dianalisis dengan menggunakan uji validitas tes dan reliabilitas tes.

\section{A. Validitas Isi}

Pengujian validitas isi instrument penelitian dilakukan dengan mempertimbangkan 2 orang ahli isi. Teknik pengujian validitas isi yang digunakan yaitu formula Gregory.

\section{B. Validitas Konstruk}

Validitas tes yang bersifat dikotomi seperti jenis tes objektif pilihan ganda, benar salah, atau menjodohkan dihitung dengan menggunakan rumus:

$$
\mathbf{Y}_{\mathbf{p b i}}=\frac{M_{p}-M_{t}}{S_{t}} \sqrt{\frac{p}{q}} \ldots \ldots
$$

Keterangan :

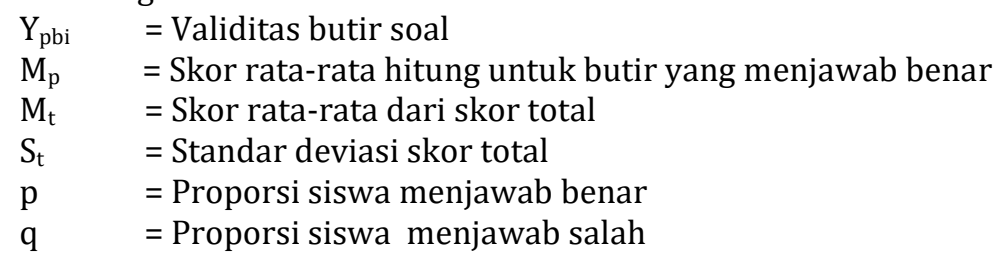

\section{Uji Reliabilitas}

Reliabilitas tes yang bersifat dikotomi dihitung dengan menggunakan rumus KR-20 atau KR-21. Apabila instrumen berupa kuesioner dengan alternative 5 jawaban maka digunakan KR-21, sedangkan apabila instrumen bernilai 0 dan 1 maka digunakan KR-20, butir-butir yang tidak valid tidak disertakan dalam perhitungan reliabilitas. 


$$
\mathbf{r}_{11}=\left(\frac{n}{n-1}\right)\left(\frac{s_{t-n \overline{p q}}^{2}}{s_{t}^{2}}\right)
$$

Keterangan :

$\mathrm{r}_{11} \quad=$ Koefisien Reliabilitas soal

$\mathrm{S}_{\mathrm{t}} \quad=$ Standar deviasi skor total

$\mathrm{p} \quad$ = Proporsi siswa menjawab benar

$\mathrm{q} \quad=$ Proporsi siswa menjawab salah

D. Uji Indeks Kesukaran Butir

Taraf kesukaran tes adalah kemampuan tes tersebut dalam menjaring banyaknya subjek peserta tes yang dapat mengerjakan dengan betul. Rumus untuk uji indeks kesukaran butir sebagai berikut.

$$
\mathrm{I}=\frac{B}{I S}
$$

Keterangan :

I = Indeks Kesukaran Butir

B = Banyak siswa menjawab benar

JS = Jumlah siswa yang mengikuti tes

E. Uji Indeks Daya Beda Butir

Indeks daya beda butir digunakan dalam membedakan peserta tes yang berkemampuan tinggi dengan peserta tes yang berkemampuan rendah.

$$
\mathrm{DB}=\frac{B a}{J a}-\frac{B b}{J b}
$$

Keterangan :

DB = Indeks daya beda tes

$\mathrm{Ba} \quad=$ Banyak kelompok atas yang menjawab butir benar

$\mathrm{Ja}=$ Banyak peserta kelompok atas

$\mathrm{Bb} \quad=$ Banyak kelompok bawah yang menjawab butir benar

$\mathrm{Jb} \quad=$ Banyak peserta kelompok bawah

F. Keefektifan Pengecoh peserta tes.

Kriteria pengecoh yang baik adalah apabila pengecoh tersebut dipilih oleh paling sedikit $5 \%$ dari

Data yang diperoleh dalam penelitian ini adalah data kuantitatif dan kualitatif. Data kuantitatif akan dianalisis dengan analisis statistik deskriptif untuk mendeskripsikan data hasil belajar dan respon siswa terhadap penggunaan model ARIAS berbantuan e-learning schoology, kemudian data kualitatif dianalisis dengan memberi makna terhadap deskripsi data. Analisis statistik yang akan digunakan berupa uji normalitas, uji homogenitas, dan uji hipotesis. Uji normalitas dilakukan dengan menggunakan analisis Chi-Square dan uji homogenitas dilakukan dengan menggunakan uji F, sedangkan uji hipotesis dilakukan untuk mengetahui apakah hipotesis alternatif yang telah diajukan diterima atau ditolak dengan menggunakan rumus polled varians. Skor rata - rata respon siswa didapatkan dengan membagi jumlah skor respon siswa dengan jumlah siswa.

\section{Hasil dan pembahasan}

Penelitian eksperimen ini bertujuan untuk mencari pengaruh penggunaan model pembelajaran ARIAS berbantuan e-learning schoology terhadap hasil belajar Teknologi Informasi dan Komunikasi (TIK) siswa kelas VIII, setelah diberikan perlakuan, selanjutnya diberikan tes akhir (posttest) pada kelompok eksperimen dan kelompok kontrol dengan tujuan untuk mengetahui hasil belajar siswa setelah diberi perlakuan. Analisis dari hasil penelitian didapat bahwa rata-rata posttest hasil belajar TIK yang dicapai siswa pada kelompok eksperimen yang menggunakan model pembelajaran ARIAS berbantuan e-learning schoology pada proses pembelajaran adalah sebesar 20,03 berdasarkan jumlah skor total pada kelas 
eksperimen dengan varians 5,59 dan standar deviasi sebesar 2,36 dengan distribusi nilai seperti pada Gambar 1 berikut.

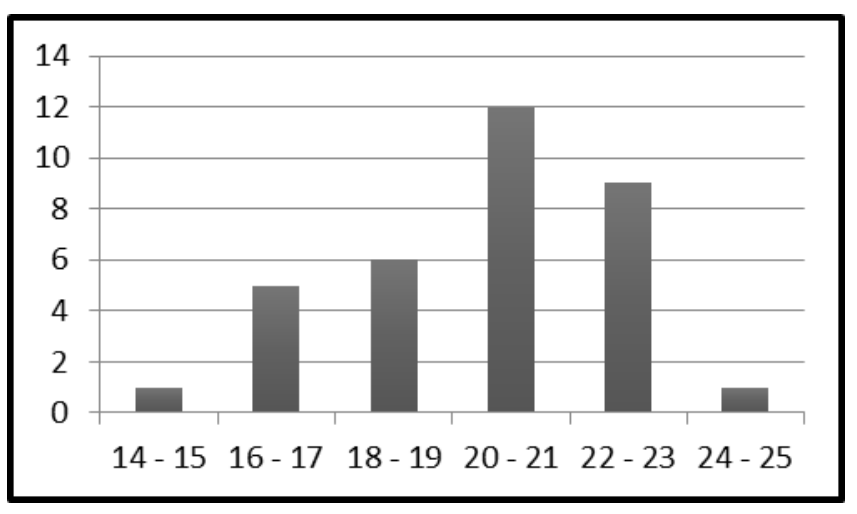

Gambar 1. Grafik Hasil Posttest Kelompok Eksperimen

Grafik pada Gambar 1 dapat dijelaskan bahwa sebanyak 1 siswa (2.94\%) memiliki skor antara 1415 , sebanyak 5 siswa (14.71\%) memiliki skor antara 16-17, sebanyak 6 siswa (17.65\%) memiliki skor 1819, sebanyak 12 siswa (35.29\%) memiliki skor 20-21, sebanyak 9 siswa (26.47\%) memiliki skor 22-23, dan sebanyak 1 siswa (2.94\%) memiliki skor 24-25. Berdasarkan distribusi nilai pada kelas eksperimen, maka kategori nilai pada kelas eksperimen dapat dikelompokkan sesuai dengan kategori pada Gambar 2.

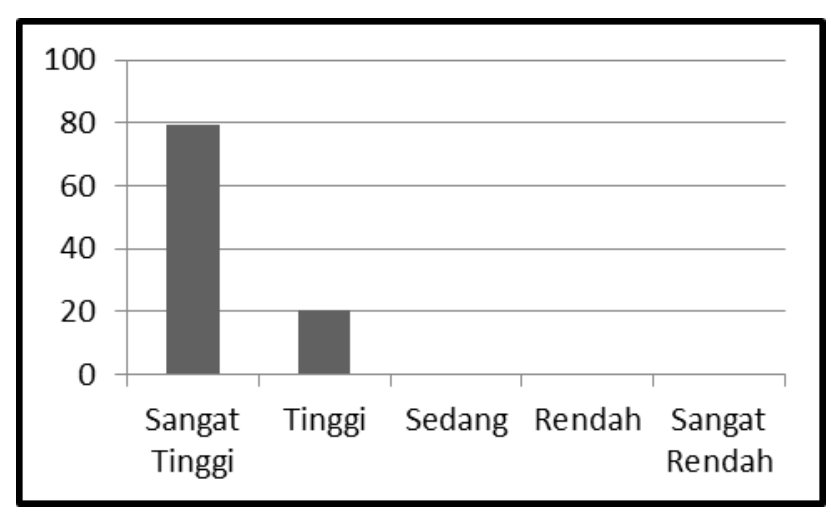

Gambar 2. Kategori Skor Posttest Kelas Eksperimen

Pada Gambar 2 dapat diketahui bahwa hasil belajar TIK kelompok eksperimen didapatkan hasil posttest sebanyak $79.41 \%$ berkategori sangat tinggi, sebanyak $20.59 \%$ berkategori tinggi dan tidak ada yang tergolong kedalam kategori sedang dan rendah serta sangat rendah.

Hasil analisis skor posttest kelompok kontrol mendapat rata-rata sebesar 17,06 berdasarkan jumlah skor total pada kelas kontrol. Varians sebesar 8,06 dan standar deviasi sebesar 2,84 dengan distribusi jumlah skor seperti pada Gambar 3.

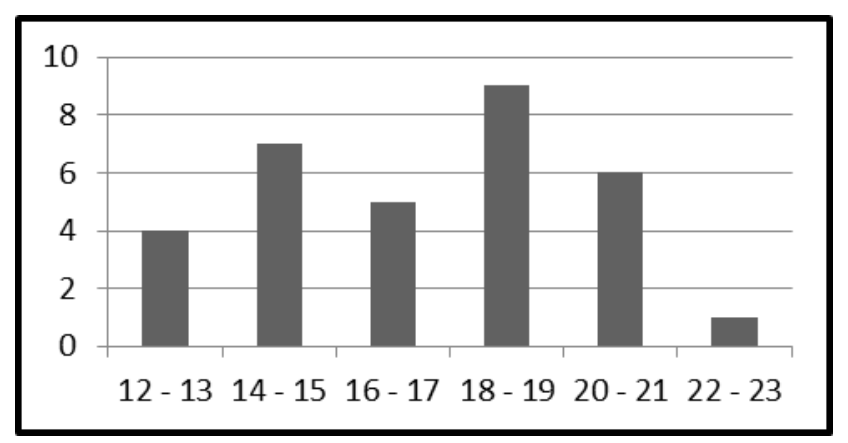

Gambar 3. Kategori Skor Posttest Kelas Kontrol 
Pada Gambar 4 dapat diketahui bahwa hasil belajar TIK kelompok kontrol hasil posttest sebanyak $34.38 \%$ berkategori sangat tinggi, sebanyak $37.50 \%$ berkategori tinggi dan sebanyak $28.12 \%$ berkategori sedang serta tidak ada yang tergolong kedalam kategori rendah dan sangat rendah.

Perhitungan uji prasyarat dilakukan dalam dua buah uji yakni normalitas dan homogenitas. Uji normalitas data hasil belajar dilakukan dengan dua jenis perhitungan yaitu dengan menggunakan Ms. Excel 2007 dan menggunakan SPSS 16.0. Hasil belajar kelompok eksperimen dengan melakukan perhitungan pada Ms. Excel 2007 mendapat hasil $x^{2}$ hitung sebesar 2,91 dan kelompok kontrol mendapat hasil $\mathrm{x}^{2}$ hitung sebesar 3,59. $\mathrm{x}^{2}$ tabel dengan $\mathrm{dk}=(6-1)=5$ dan taraf signifikan $5 \%$ adalah sebesar 11,07 , dengan demikian data kelas eksperimen dan kelas kontrol dinyatakan berdistribusi normal karena $\mathrm{x}^{2}$ hitung $<\mathrm{x}^{2}$ tabel yang ditunjukkan pada Tabel 2 .

Tabel 2. Rangkuman Hasil Uji Normalitas dengan Ms. Excel 2007

\begin{tabular}{lccc}
\hline \multicolumn{1}{c}{ Sampel } & $\boldsymbol{\chi}^{2}$ hitung & $\boldsymbol{\chi}^{2}$ tabel & Keterangan \\
\hline Kelompok Eksperimen & 2.91 & 11.07 & Normal \\
Kelompok Kontrol & 3.59 & 11.07 & Normal \\
\hline
\end{tabular}

Selain menggunakan Ms. Excel 2007 perhitungan uji normalitas juga dilakukan dengan menggunakan SPSS 16.0 dengan hasil seperti pada Tabel 3.

Tabel 3. Rangkuman Hasil Uji Normalitas dengan SPSS 16.0

\begin{tabular}{lcccc}
\hline \multicolumn{1}{c}{ Kelompok } & Kolmogorov-Smirnov & Shapiro-Wilk & Sig & Keterangan \\
\hline Eksperimen & 0,044 & 0,078 & 0,05 & Normal \\
Kontrol & 0,173 & 0,125 & 0,05 & Normal \\
\hline
\end{tabular}

Hasil uji normalitas menggunakan SPSS 16.0 menunjukkan bahwa angka signifikan kelompok eksperimen dan kelompok kontrol lebih besar dari 0,05 sehingga kedua data hasil belajar tersebut dikatakan berdistribusi normal.

Perhitungan selanjutnya adalah uji homogenitas menggunakan uji-f sehingga mendapat hasil $F_{\text {hitung }}=1,44$. Derajat kebebasan (dk) untuk pembilang adalah 32-1=31 dan derajat kebebasan (dk) untuk penyebut adalah 34-1=33 dengan taraf signifikan 5\%, maka diperoleh $\mathrm{F}_{\text {tabel }}=1.8$. Dalam hal ini berlaku ketentuan, bila harga $\mathrm{F}_{\text {hitung }}$ lebih kecil atau sama dengan $\mathrm{F}_{\text {tabel }}\left(\mathrm{F}_{\text {hitung }} \leq \mathrm{F}_{\text {tabel }}\right)$, maka $\mathrm{H}_{0}$ diterima dan $\mathrm{H}_{1}$ ditolak sehingga varians dikatakan homogen. Selain itu, uji homogenitas juga dilakukan dengan SPSS 16.0 dengan hasil 0,086 yang berarti homogeny karena lebih besar dari taraf signifikan yaitu 0,05.

Berdasarkan data yang diperoleh kelompok eksperimen dan kelompok kontrol telah berdistribusi normal dan data homogen maka dilanjutkan dengan melakukan uji hipotesis dengan menggunakan uji-t. Uji-t dapat dihitung dengan menggunakan Ms. Excel 2007 dan SPSS 16.0. Uji-t dengan Ms. Excel 2007 dihitung menggunakan rumus Polled Varians sebagai berikut.

$$
\begin{gathered}
\mathrm{t}=\frac{\bar{x}_{1}-\bar{x}_{2}}{\sqrt{\frac{\left(n_{1}-1\right) S_{1}^{2}+\left(n_{2}-1\right) S_{2}^{2}}{n_{1}+n_{2}-2}\left(\frac{1}{n_{1}}+\frac{1}{n_{2}}\right)}} \\
t=\frac{20.09-17.03}{\sqrt{\frac{(84-1) 5.59+(32-1) g .06}{84+82-2}\left(\frac{1}{g 4}+\frac{1}{g 2}\right)}} \\
\mathrm{t}=\frac{3.06}{0.6417} \\
\mathrm{t}=4.7686
\end{gathered}
$$

Berdasarkan perhitungan tersebut memperoleh $t_{\text {hitung }}$ sebesar 4,7686. Nilai $t_{\text {tabel }}$ dengan $\mathrm{db}=64$ dengan taraf signifikan $5 \%$ adalah sebesar 1,9977. Berdasarkan perhitungan uji-t diperoleh $t_{\text {hitung }}>\mathrm{t}_{\text {tabel }}$ $(4,7686>1,9977)$ maka $\mathrm{H}_{0}$ ditolak, berarti $\mathrm{H}_{1}$ diterima. Berdasarkan hal ini dapat diartikan bahwa terdapat hasil belajar yang lebih tinggi antara siswa yang belajar menggunakan model pembelajaran ARIAS berbantuan $e$ - learning schoology dengan siswa yang belajar tanpa menggunakan model pembelajaran ARIAS berbantuan e-learning schoology pada mata pelajaran TIK kelas VIII SMP Saraswati Seririt. Uji-t juga dihitung dengan menggunakan SPSS 16.0 dengan hasil sebagai berikut. 
Tabel 4. Uji Hipotesis dengan SPSS 16.0

\begin{tabular}{llccc}
\hline & & \multicolumn{3}{c}{ t-test for Equality of Means } \\
\cline { 3 - 5 } & Equal variances assumed & t & Df & $\begin{array}{c}\text { Sig. } \\
\text { (2tailed) }\end{array}$ \\
\hline \multirow{2}{*}{ Nilai } & 4.714 & 64 & 0.000 \\
& Equal variances not assumed & 4.681 & 59.217 & 0.000 \\
\hline
\end{tabular}

Hasil uji hipotesis dengan uji-t menggunakan SPSS 16.0 didapatkan nilai signifikan sebesar 0,000. Oleh karena itu probabilitas signifikan $<0,05$, maka $\mathrm{H}_{1}$ diterima, sehingga dapat dikatakan bahwa terdapat hasil belajar yang lebih tinggi antara siswa yang belajar menggunakan model pembelajaran ARIAS berbantuan e-learning schoology dengan siswa yang belajar tanpa menggunakan model pembelajaran ARIAS berbantuan e-learning schoology pada mata pelajaran TIK kelas VIII SMP Saraswati Seririt.

\section{A. Hasil Belajar}

Berdasarkan seluruh penemuan yang diperoleh baik dari analisis deskriptif maupun berdasarkan hasil analisis uji-t, maka dapat diambil suatu keputusan bahwa model pembelajaran ARIAS berbantuan $e$ learning schoology memberikan pengaruh yang lebih baik dibandingkan dengan pembelajaran tanpa menggunakan model pembelajaran ARIAS berbantuan e-learning schoology.

Berdasarkan pertimbangan-pertimbangan teoritik dan operasional, maka implikasi dari penelitian ini jika dilihat dari teori konstruktivisme adalah proses belajar dan pembelajaran dikelas harus berjalan secara efektif dan menyenangkan. Penggunaan model pembelajaran ARIAS berbantuan e-learning schoology dalam proses pembelajaran Teknologi Informasi dan Komunikasi (TIK) membuat siswa menjadi siswa lebih cepat mengerti dalam proses pembelajaran, karena siswa mendapat pengalaman baru dalam proses belajar serta menumbuhkan rasa kepercayaan diri (self-efficacy) siswa. Kemampuan menilai dirinya secara akurat merupakan hal yang sangat penting dalam mengerjakan tugas dan pertanyaanpertanyaan yang diajukan oleh guru, dengan self-efficacy dapat memudahkan siswa dalam menyelesaikan tugas tersebut dengan terstruktur dan terarah, bahkan lebih dari itu mampu meningkatkan hasil belajarnya. Permasalahan selama ini guru cenderung memberikan penjelasan materi dan soal-soal latihan dengan model konvensional yang dapat membuat siswa merasa bosan, sehingga dengan penggunaan model pembelajaran ARIAS berbantuan e-learning schoology memberikan sebuah inovasi terbaru dalam dunia pendidikan pada khususnya. E-learning schoology ini dirancang juga untuk mempersiapkan dan melatih kemampuan siswa belajar dalam menghadapi Ujian Nasional pada saat kelas IX yang sistem ujiannya berbasis online.

\section{B. Respon Siswa}

Hasil analisis respon siswa terhadap penggunaan model pembelajaran ARIAS berbantuan $e$ learning schoology berada pada kategori sangat positif dengan rata-rata yang didapat dari jumlah skor respon siswa pada kelas eksperimen. Keadaan seperti ini dapat dijadikan awal dalam menciptakan suasana belajar yang efektif agar bisa meningkatkan hasil belajar siswa yang lebih tinggi. Respon positif dari siswa akan menjadi langkah awal untuk menuju lingkungan belajar yang lebih efektif. Jadi dengan diperoleh respon siswa yang sangat positif terhadap penggunaan model pembelajaran ARIAS berbantuan e-learning schoology pada mata pelajaran TIK di dalam kelas dapat dikatakan bahwa model pembelajaran ARIAS berbantuan e-learning schoology dapat diterima dengan baik oleh siswa dan dapat dijadikan sebagai langkah alternative dalam pembelajaran dikelas.

\section{Simpulan dan saran}

Berdasarkan paparan hasil penelitian dan pembahasan dapat disimpulkan sebagai berikut, belajar menggunakan model pembelajaran ARIAS berbantuan e-learning schoology pada mata pelajaran TIK kelas VIII di SMP Saraswati Seririt memiliki hasil belajar yang lebih tinggi dengan siswa yang belajar tanpa menggunakan model pembelajaran ARIAS berbantuan e-learning schoology. Hal ini dapat dilihat dari hasil pengujian hipotesis menggunakan analisis uji-t dimana $t_{\text {hitung }}=4,7686>$ dari $t_{\text {tabel }}=1,9977$ maka $\mathrm{H}_{0}$ ditolak atau $\mathrm{H}_{1}$ diterima.

Hasil analisis respon siswa dari penggunaan model pembelajaran ARIAS berbantuan e-learning schoology pada mata pelajaran TIK adalah sangat positif dilihat dari rata-rata skor hasil angket respon siswa yaitu sebesar 83,89 . 


\section{Daftar Rujukan}

Arsyad, A. (2011). Media Pembelajaran. Jakarta: PT Raja Grafindo Persada.

Rahman, M., \& Amri, S. (2014). Model Pembelajaran ARIAS Terintegratif. Jakarta: PT. Prestasi Pustakarya.

Sugihartini, N. (2016). Strategi Pembelajaran Pendekatan Inovatif Disertai dengan Aplikasi Pembelajaran Bidang Teknologi Informasi dan Komunikasi (TIK). Singaraja: Undiksha Press.

Purwaningsih, \& dkk. (2016). Pengaruh Penggunaan E-Learning Dengan Schoology Terhadap Hasil Belajar Peserta Didik. Jurnal Of Education .

Slameto. (2003). Belajar dan Faktor - Faktor Yang Mempengaruhinya. Jakarta: Rineka Cipta.

Sardiman. (2001). Interaksi \& Motivasi Belajar Mengajar. Jakarta: Raja Grafindo Persada.

Sugihartini, N., \& Agustini, K. (2017). Asesmen Otentik Sebagai Pendukung Desain Instruksional Jaringan Komputer Berstrategi Blended-Learning dengan Pendekatan Konstruktivistik. Journal of Education Action Research .

Nasution, S. (2003). Metode Penelitian Naturalistik Kualitatif. Bandung: Tarsito.

Rusman. (2012). Model Model Pembelajaran Mengembangkan Profesionalisme Guru. Jakarta: Raja Grafindo Persada.

Sudaryono, Margono, G., \& Rahayu, W. (2013). Pengembangan Instrumen Penelitian Pendidikan. Yogyakarta: Graha Ilmu.

Divayana, D. G. (2017). Buku Ajar Asesmen dan Evaluasi. Singaraja: Undiksha Press.

Candiasa, I. M. (2010). Statistik Multivariat Disertai Aplikasi SPSS. Singaraja: Unit Penerbit Undiksha.

Turnip, B., \& Khairani, Z. (2016). Pengaruh Model Pembelajaran ARIAS (Assurance, Relevance, Interest, Assessment, Satisfaction) Terhadap Hasil Belajar Siswa Pada Materi Pokok Listrik Dinamis Di Kelas X SM II SMA Cerdas Murni T.P 2014/2015. Jurnal Ikatan Alumni Fisika Universitas Negeri Medan, Vol.2 No1.

Sancoko, M., Aunillah, \& Kurniawan, L. (2016). Studi Komparatif Strategi Belajar ARIAS dan Strategi Belajar VAK. Jurnal Pendidikan Matematika STKIP PGRI Sidoarjo , Vol.1 No.1.

Yuliana, D., \& Jufri, F. A. (2019). Pengaruh E-Learning Berbasis Schoology Terhadap Aktivitas Belajar Peserta Didik Kelas X Jurusan Teknik Komputer Dan Jaringan SMK Sumber Bunga. Jurnal Pendidikan Sains dan Teknologi , Vol.1 No.1.

Ningsih, W. S., Suana, W., \& Maharta, N. (2018). PENGARUH PENERAPAN BLENDED LEARNING BERBASIS SCHOOLOGY TERHADAP KEMAMPUAN BERPIKIR KRITIS SISWA. Konstan Jurnal Fisika Dan Pendidikan Fisika, Vol 3 No 2.

Ulva, N. L., Kantun, S., \& Widodo, J. (2017). Penerapan E-Learning Dengan Media Schoology Untuk Meningkatkan Motivasi Dan Hasil Belajar Siswa Pada Kompetensi Dasar Mendeskripsikan Konsep Badan Usaha Dalam Perekonomian Indonesia. Jurnal Ilmiah Ilmu Pendidikan, Ilmu Ekonomi, dan Ilmu Sosial , Vol.11 No.2. 